\title{
Penentuan kualitas mutu air sungai Kampwolker Jayapura dengan metode STORET
}

\author{
Wiher Haerati ${ }^{1^{*}}$, Auldry F. Walukouw ${ }^{2}$ \\ ${ }^{1}$ Program Studi Pendidikan Fisika UniversitasCenderawasih, Jayapura-Papua \\ ${ }^{2}$ Program Pascasarjana Universitas Cenderawasih, Jayapura-Papua \\ *Koresponden E-mail: wiherhaeraty@gmail.com
}

(Diterima: 06 Juni 2021|Disetujui: 17 Januari 2022|Diterbitkan: 31 Januari 2022)

\begin{abstract}
The condition of the waters in Papua is that there are various kinds of marine life in the body of water. One of the water bodies is the Kampwolker River which has a length of $14.15 \mathrm{~m}$ with an intlet river (a river that empties into Lake Sentani) which is located in the Kampwolker River watershed to Jl. 2 Expo Arena, Waena. It turns out that the Kampwolker River has a heavily polluted result with a score of 48. GPS and Arcgis Software Version 10.3 show three locations of the Kampwolker river, including: the intake Kampwolker River, the middle Kampwolker River, and the downstream Kampwolker River. Water quality was measured using the STORET method. Analysis of water samples obtained several samples of the most dominantly high chemical parameters, including Phosphate (PO4 - P) of $2.48 \mathrm{mg} / \mathrm{l}$, Copper (Cu) of $0.235 \mathrm{mg} / \mathrm{l}$, and Lead (Pb) of $0.15 \mathrm{mg} / \mathrm{l}$. l. Kampwolker river pollution shows a color change to brown. This is due to the activities of densely populated community settlements, the agricultural industry, mineral $C$ mining, and other industrial fields. Floods and erosion occur due to the ignorance of the community around the Kampwolker river to the importance of ecosystems and drinking water sources for the survival of the people in Jayapura City.
\end{abstract}

Keywords: Kampwolker River; phosphate; $\mathrm{Cu}$; $\mathrm{Pb}$; erosion; community activities

\section{PENDAHULUAN}

Kondisi perairan di Papua sangatlah beranekaragam macam biota yang ada di badan air. Salah satu badan air yang sangat dibutuhkan oleh semua makhluk hidup adalah sungai Kampwolker. Sungai Kampwolker merupakan salah satu dari 14 sungai yang bermuara di danau Sentani, Papua. Sungai ini mengalir menuruni lereng pegunungan Cycloop dari arah Utara ke Selatan yang memiliki panjang $14,15 \mathrm{~km}$ yang hulunya terletak di kawasan pegunungan $\mathrm{Cy}$ cloop dan hilirnya di daerah Gelanggang 2 Expo, Waena (Mujiati, 2017). Sungai ini memiliki kawasan pemukiman dari Jalan Kampwolker sampai pada Jalan Gelanggang 2 Expo, Waena. Kondisi Sub Daerah Aaliran Sungai (DAS) Kampwolker sangatlah dibutuhkan oleh masyarakat dimana dijadikan sebagai wadah yang sangat krusial pada sektor-sektor kehidupan masyarakat. Sektor-sektor tersebut antara lain sebagai tempat tinggal masyarakat (pemukiman), sektor pembangunan formal, penggerakan ekonomi dalam mata pencaharian masyarakat seperti penambang batu, nelayan, pencari suaka biota yang berada di danau dan lain-lain. Dalam kehidupan sehari-hari sungai kampwolker termasuk sungai yang digunakan untuk aktivitas sehari-hari masyarakat disekitarnya, seperti mencuci pakaian, mencuci motor, sebagai tempat mandi, bahkan sebagai mata air yang digunakan untuk minum oleh masyarakat disekitar lingkungan tersebut. Namun, banyak permasalahan yang dapat menghancurkan aliran DAS sebagaimana sungai termasuk bagian dari kelangsungan kehidupan manusia itu sendiri. Masalah tersebut dari penggunaan Sungai Kampwolker, yaitu banyak penambangan galian C, degredasi tanah, adanya aktivitas pupuk pestisida yang berlebihan juga banyaknya lahan kosong menjadi pemukiman aktivitas masyarakat kehidupan sehari-hari seperti limbah IPAL seperti Septic tank yang dibuang ke sungai, mencuci piring, pakaian dan lain-lain sehingga ada beberapa parameter yang membuat sungai tercemar antara lain, COD sebesar $(10,00-15,00$ $\mathrm{mg} / \mathrm{L})$, DO sebesar $(6,00-6,40 \mathrm{mg} / \mathrm{L})$, phospat $\left(\mathrm{PO}_{4}-\right.$ P) sebesar, $(0,71-0,94 \mathrm{mg} / \mathrm{L})$ tembaga $(\mathrm{Cu})$ sebesar $(0,045-0,105 \mathrm{mg} / \mathrm{l})$ dan timbal $(\mathrm{Pb})$ sebesar $(0,045-$ $0,105 \mathrm{mg} / \mathrm{l})$. Data tersebut dihasilkan dari lima parameter dari tiga titik sampling, yaitu Sungai Kampwolker bagian intake, sungai Kampwolker bagian tengah, dan sungai Kampwolker bagian hilir. Permasalahan utama pada sungai Kampwolker adalah kualitas air sungai Kampwolker yang tercemar sehingga dapat memberikan kerugian yang besar bagi sumber daya alam maupun manusia untuk generasi sekarang maupun yang akan datang.

Degradasi lingkungan DAS Sentani harus ditanggulangi dengan pendekatan sistem yang kompleks. Oleh karena berkaitan dengan penduduk dan kebutuhannya, seperti penduduk dengan pemukiman, pekerjaan, aktivitas pertanian, dan masalah lingkungan. Begitu pula sumber pencemar Danau Sentani 
disebabkan oleh berbagai hal dan berlanjut secara terus menerus dalam fungsi waktu (Walukouw, 2012).

Beberapa penelitian sebelumnya tentang pencemaran sungai dan danau, melaporkan bahwa pada Danau Sentani yang berasal dari sungai (inlet) terjadi erosi tanah yang memasuki badan air dapat menimbulkan dampak negatif, yakni peningkatan kandungan unsur hara diperairan (Walukow, 2017). Pencemaran di sungai Kampwolker berkaitan dengan beban pencemaran karena unsur hara, pestisida, dan bahan-bahan organik yang dapat mencemari air (Mujiati, 2015).

Walukouw (2016) melaporkan bahwa terjadi pencemaran air oleh parameter $\mathrm{Cu}$ sebesar $\mathrm{Cu}(0,020$ $0,054 \mathrm{mg} / \mathrm{l}$ ) dan rata-rata pencemaran air oleh $\mathrm{Pb}$ dari beberapa titik sungai Kampwolker, hingga muara ke Danau Sentani sebesar adalah (4,0-28 mg /1). Pemeriksaan rutin terhadap air sungai maupun danau diperlukan untuk memastikan parameter yang dihasilkan tidak melebihi peraturan Menteri Kesehatan atau peraturan gubernur Papua melalui badan lingkungan hidup upaya menjada produksi air bersi yang memenuhi standar kualitas penting untuk menjaga aspek kesehatan sebagai sumber air minum.

Standar kualitas air yang disetujui oleh pemerintah dalam Peraturan Pemerintah No. 82 tahun 2001 tentang pengelolaan kualitas air dan pengendalian pencemaran air. Sejalan dengan turunnya status kualitas air yang disebabkan oleh parameter polusi fisik dan kimia, ini sejalan dengan penelitian sebelumnya (Walukouw, 2017).
Begitu pula Pencemaran air menyebutkan degradasi lingkungan perairan sungai dan danau sangat dipengaruhi oleh subsistem populasi penduduk, sumberdaya air, industri, polusi (pencemaran), kualitas air, pariwisata dan pertanian (Walukouw et al., 2008). Penelitian tersebut masih menggunakan analisis kualitatif karena penelitian pada sungai Kampwolker hanya bersubjek pada dampak pencemaran air Sungai Kampwolker. Metode STORET memiliki keunggulan yakni dapat menggabungkan secara bersama beberapa titik sampling dalam analisis, sehingga akan didapat informasi status mutu air tercemar ringan, sedang, dan berat.

\section{BAHAN DAN METODE}

Penelitian berlangsung pada tahun 2019 .Pengambilan sampel pada tanggal 11 -12 April 2019 dimulai dari jam 07.25 WIT sampai 14.45 WIT dengan kondisi cuaca cerah. Sungai Kampwolker memiliki titik koordinat secara geografis dinyatakan dengan koordinat $2^{\circ} 32^{\prime} 28.96 " \mathrm{LS}$ dan $140^{\circ} 37^{\prime} 34.65^{\prime \prime} \mathrm{BT}$ dengan menggunakan software ArcGIS . Metode yang digunakan yaitu STORET yang dianalisis untuk mengukur kualitas mutu air dengan cara mengambil sampel air menggunakan perahu motor tempel. Parameter yang diukur meliputi variabel kualitas air yang diukur dan di analisis dengan menggunakan peralatan pada Tabel 1.

Tabel 1. Variabel kualitas air yang diukur, analisisnya dan alat yang dipergunakan

\begin{tabular}{|c|c|c|c|c|c|c|c|c|}
\hline \multirow[t]{3}{*}{ No } & \multirow[t]{3}{*}{ Parameter } & \multirow[t]{3}{*}{ Satuan } & \multirow{2}{*}{\multicolumn{4}{|c|}{ Baku Mutu }} & \multirow[t]{3}{*}{ Alat } & \multirow[t]{3}{*}{ Metode } \\
\hline & & & & & & & & \\
\hline & & & Kelas I & Kelas II & Kelas III & Kelas IV & & \\
\hline 1. & $\mathrm{PH}$ & - & $6-9$ & $6-9$ & $6-9$ & $5-9$ & $\mathrm{pH}$ meter & Potensiometrik, in situ \\
\hline 2. & $\mathrm{DO}$ & $\mathrm{mg} / 1$ & 6 & 4 & 3 & 0 & $\begin{array}{c}\text { Peralatan } \\
\text { titrasi/DO meter }\end{array}$ & $\begin{array}{c}\text { Titrasi Winkier, } \\
\text { Laboratorium/ in situ }\end{array}$ \\
\hline 3. & $\mathrm{BOD}_{5}$ & $\mathrm{mg} / 1$ & 2 & 3 & 6 & 12 & Peralatan titrasi & Titrasi, Laboratorium \\
\hline 4. & COD & $\mathrm{mg} / 1$ & 10 & 25 & 50 & 100 & Peralatan titrasi & Titrasi, Laboratorium \\
\hline 5. & Flourida (F) & $\mathrm{mg} / 1$ & 0,5 & 1,5 & 1,5 & - & Spektrometer vis & Spektrometri \\
\hline 6. & $\begin{array}{c}\mathrm{NO}_{3} \text { sebagai } \\
\mathrm{N}\end{array}$ & $\mathrm{mg} / 1$ & 0,5 & - & - & - & Spektrometer vis & Spektrometri \\
\hline 7. & $\mathrm{PO}_{4}-\mathrm{P}$ & $\mathrm{mg} / 1$ & & & & & Spektrometer vis & Spektrometri \\
\hline 8. & Besi(Fe) & $\mathrm{mg} / 1$ & 0,3 & - & - & - & Spektrometer vis & Spektrometri \\
\hline 9. & $\begin{array}{l}\text { Cadmium } \\
\text { (Cd) }\end{array}$ & $\mathrm{mg} / 1$ & 0,01 & 0,01 & 0,01 & 0,01 & Spektrometer vis & Spektrometri \\
\hline 10. & $\begin{array}{l}\text { Chromium } \\
\text { (Cr valensi } \\
6 \text { ) }\end{array}$ & $\mathrm{mg} / 1$ & 0,05 & 0,05 & 0,05 & 0,01 & SAA-Nyala & Spektrometri \\
\hline 11. & Kobalt (Co) & $\mathrm{mg} / 1$ & 0,2 & 0,2 & 0,2 & 0,2 & Spektrometer vis & Spektrometri \\
\hline 12. & Timbal (Pb) & $\mathrm{mg} / 1$ & 0,03 & 0,03 & 0,03 & 1 & SAA-Nyala & Spektrometri \\
\hline 13. & $\begin{array}{l}\text { Tembaga } \\
(\mathrm{Cu})\end{array}$ & $\mathrm{mg} / 1$ & 0,02 & 0,02 & 0,02 & 0,2 & Spektrometer vis & Spektrometri \\
\hline
\end{tabular}

Sumber : Hasil Analisis 
Muara sungai Kampwolke dilakukan pengambilan sampel pada masing-masing sungai yang mengairi ke Danau Sentani yang dilakukan 3 kali ulangan. Di lokasi sungai, penelitian diawali dengan penentuan lokasi pengambilan sampel dengan mempertimbangan dapat mewakili aktivitas didaratan, dan aktivitas di perairan yaitu adanya aktivitas pencucian mobil di sungai, penambangan galian $C$ dan emas, pemukiman padat di sekitar sungai, erosi lahan, jalur transportasi air dan stasiun pantai danau, aktivitas konversi lahan di hulu, dan PLTD. Pengambilan sampel air dilakukan dengan menggunakan botol sampel di tiga lokasi titik, yaitu air sungai Kampwolker (intake), air sungai Kampwolker bagian tengah, dan air sungai Kampwolker bagian hilir. Penentuan tiga lokasi dari sungai Kampwolker. Sampling tersebut berdasarkan beberapa aspek, yaitu tujuan pengambilan. sampel, kualitas mutu air yang disampel, metode yang digunakan dalam pengambilan sampel, dan parameter dan perhitungan yang akan di sampel, khususnya air permukaan. Posisi titik koordinat (lintang-bujur) lokasi sampling atau masing-masing stasiun pengamatan ditentukan dengan menggunakan GPS (Global Posisioning System) dan Software Arcgis version 10.3

Untuk menentukan status mutu perairan di Sentani digunakan metode STORET. Rujukan tersebut berdasarkan pada KepMen LH Nomor 115 Tahun
2003, metode STORET merupakan salah satu mutu air yang digunakan untuk tingkatan klasifikasi mutu parameter yang telah memenuhi atau melampaui baku mutu air. Penentuan status mutu air dengan sistem STORET dimaksudkan sebagai acuan dalam melakukan pemantauan kualitas air sungai dengan tujuan mengetahui mutu suatu sistem akuatik secara analisis dalam bentuk parameter fisika, kimia, dan biologi. Penentuan status mutu air adalah dengan menggunakan sistem nilai dari "US-EPA (Environmental Protection Agency)" dengan mengklasifikasikan mutu air dalam empat kelas, yaitu :

1. Kelas A: baik sekali, skor $=0$ memenuhi baku mutu

2. Kelas $B$ : baik, skor $=-1 \mathrm{~s} / \mathrm{d}-10$ cemar ringan

3. Kelas $C$ : sedang, skor $=-11 \mathrm{~s} / \mathrm{d}-30$ cemar sedang

4. Kelas D : buruk, skor $=-31$ cemar berat.

Penentuan status mutu air dengan menggunakan metode STORET ini dilakukan dengan langkah-langkah a) membandingkan data hasil pengukuran dari masing-masing parameter air dengan nilai baku mutu yang sesuai dengan kelas air; b) jika hasil pengukuran memenuhi nilai baku mutu (hasil pengukuran < baku mutu) maka di beri 0; c) jika hasil pengukuran tidak memenuhi baku mutu air (hasil pengukuran $>$ baku mutu) maka diberi skor (Tabel 2).

Tabel 2. Pengukuran kualitas baku mutu air dengan metode STORET

\begin{tabular}{|c|c|c|c|c|c|c|c|c|c|c|c|c|c|}
\hline \multirow[t]{2}{*}{ No } & \multirow[t]{2}{*}{ Parameter } & \multirow[t]{2}{*}{ satuan } & \multirow{2}{*}{$\begin{array}{l}\text { Baku } \\
\text { mutu }\end{array}$} & \multirow{2}{*}{$\begin{array}{c}\text { Titik } \\
1\end{array}$} & \multirow{2}{*}{$\begin{array}{c}\text { Titik } \\
2\end{array}$} & \multirow[t]{2}{*}{ Titik 3} & \multicolumn{3}{|c|}{ Hasil pengukuran } & \multicolumn{3}{|l|}{ Nilai } & \multirow{2}{*}{ skor } \\
\hline & & & & & & & Min & Max & Rat & Min & $\max$ & Rat & \\
\hline 1. & $\mathrm{PH}$ & - & 60 & 8,31 & 7,99 & 7,89 & 7,89 & & 8,06 & 0 & 0 & 0 & 0 \\
\hline 2. & $\mathrm{BOD}_{5}$ & $\mathrm{mg} / 1$ & $0-9$ & 1,90 & 2,00 & 2,1 & 1,90 & 210 & 2,00 & 0 & -2 & 0 & -2 \\
\hline 3. & $\mathrm{COD}$ & $\mathrm{mg} / 1$ & 10,00 & 10,00 & 10,00 & 15,00 & 10,00 & 15,00 & 11,67 & 0 & -2 & -6 & -8 \\
\hline 4. & DO & $\mathrm{mg} / 1$ & $\geq 6,00$ & 6,00 & 6,00 & 6,40 & 6,00 & 6,40 & 6,13 & 0 & -2 & -6 & -8 \\
\hline 5. & $\begin{array}{l}\text { Flourida } \\
\text { (F) }\end{array}$ & $\mathrm{mg} / 1$ & 0,50 & 0,21 & 0,26 & 0,32 & 0,21 & 0,32 & 0,26 & 0 & 0 & 0 & 0 \\
\hline 6. & $\begin{array}{c}\mathrm{NO}_{3} \\
\text { sebagai } \mathrm{N}\end{array}$ & $\mathrm{mg} / 1$ & 10,0 & 0,70 & 1,4 & 1,6 & 0,7 & 1,6 & 1,23 & 0 & 0 & 0 & 0 \\
\hline 7. & $\mathrm{PO}_{4}-\mathrm{P}$ & $\mathrm{mg} / 1$ & 0,2 & 0,71 & 0,83 & 0,94 & 0,71 & 0,94 & 0,82 & -2 & -2 & -6 & -10 \\
\hline 8. & $\operatorname{Besi}(\mathrm{Fe})$ & $\mathrm{mg} / 1$ & 0,3 & 0,04 & 0,07 & 0,06 & 0,044 & 0,07 & 0,05 & 0 & 0 & 0 & 0 \\
\hline 9. & $\begin{array}{l}\text { Cadmium } \\
\text { (Cd) }\end{array}$ & $\mathrm{mg} / 1$ & 0,01 & 0,00 & 0,00 & 0,00 & 0,00 & 0,00 & 0,00 & 0 & 0 & 0 & 0 \\
\hline 10. & $\begin{array}{c}\text { Chromium } \\
\text { (Cr valensi } \\
6 \text { ) }\end{array}$ & $\mathrm{mg} / 1$ & 0,05 & 0,004 & 0,013 & 0,013 & 0,004 & 0,01 & 0,01 & 0 & 0 & 0 & 0 \\
\hline 11. & $\begin{array}{c}\text { Kobalt } \\
\text { (Co) }\end{array}$ & $\mathrm{mg} / 1$ & 0,02 & 0,005 & 0,008 & 0,022 & 0,005 & 0,022 & 0,016 & 0 & 0 & 0 & 0 \\
\hline 12. & $\begin{array}{l}\text { Timbal } \\
(\mathrm{Pb})\end{array}$ & $\mathrm{mg} / 1$ & 0,03 & 0,014 & 0,038 & 0,098 & 0,014 & 0,098 & 0,05 & -2 & -2 & -6 & -10 \\
\hline 13. & $\begin{array}{l}\text { Tembaga } \\
(\mathrm{Cu})\end{array}$ & $\mathrm{mg} / 1$ & 0,02 & 0,045 & 0,085 & 0,105 & 0,045 & 0,105 & 0,078 & -2 & -2 & -6 & -10 \\
\hline & & & & & Jur & lah Skor & & & & & & & -48 \\
\hline
\end{tabular}




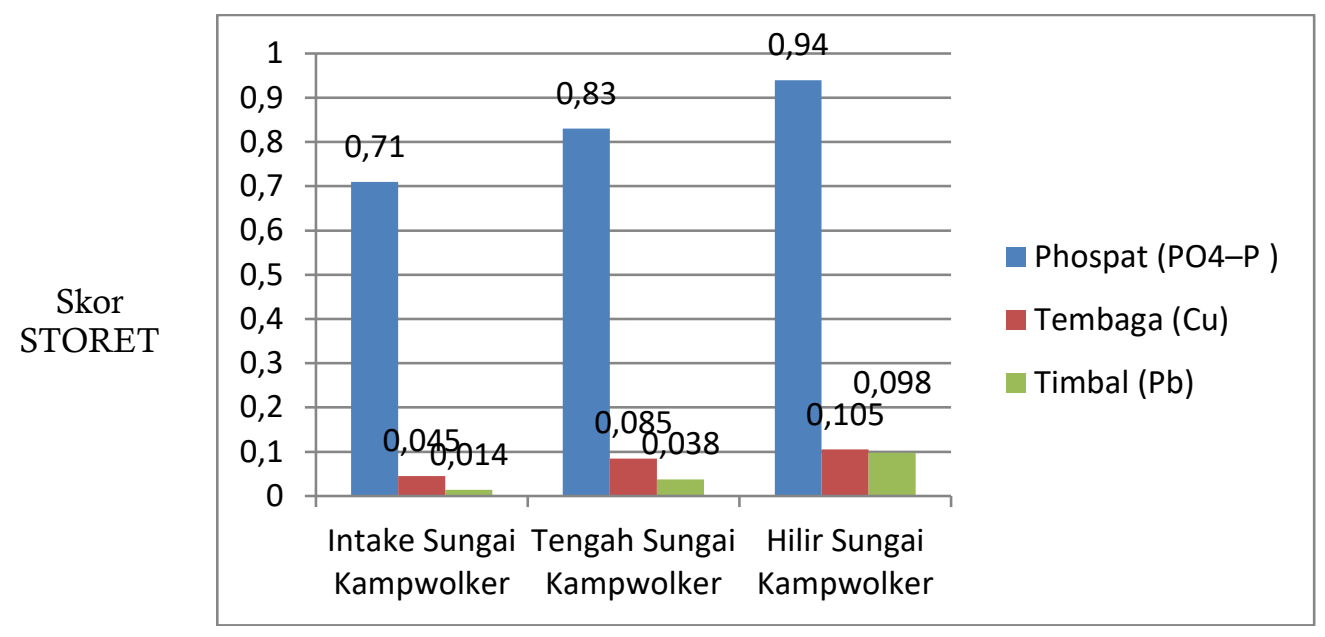

Gambar 1. Grafik status mutu air Sungai Kampwolker dengan tiga dominan parameter fisika

\section{HASIL DAN PEMBAHASAN}

Hasil perhitungan status mutu air sungai Kampwolker dengan penentuan metode STORET untuk masing-masing lokasi menunjukkan bahwa air Sungai Kampwolker telah tercemar berat (Tabel 2). Penentuan pada skor mutu air dipengaruhi pada beberapa kegiatan masyarakat hulu dan hilir sungai Kampwolker ke arah muara danau Sentani sangatlah padat . Kegiatan yang dilakukan sehari-hari oleh masyarakat lingkungan sungai Kampwolker menjadi tempat wadah untuk kelangsungan hidupnya sebagai contoh tempat kebutuhan rumah tangga, misalnya mandi, sanitasi mencuci (pakaian, kendaraan, alat makan) dan sumber air minum dalam usaha mikro menengah (depot air minum). Selain sebagai kebutuhan rumah tangga juga sebagai mata pencaharian pada masyarakat di sekitar sungai Kampwolker. Contoh dalam bidang pertanian, bidang pertambangan galian C, bidang perikanan, bidang industri dan faktor alamiah kandungan tanah sekitar sungai Kampwolker.

Tingginya pencemaran air sungai Kampwolker berubah warna menjadi coklat pada saat curah hujan yang sedang-tinggi, sehingga adanya banjir dan erosi di sekitar sungai akibat kebakaran hutan dan penebangan liar, serta kurangnya partisipasi masyarakat untuk lencana Reboisasi, dan banyaknya limbah di sungai Kampwolker terutama limbah plastik kemasan

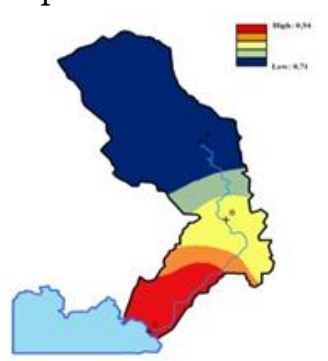

Gambar 1. (Parameter $\mathrm{PO}_{4}-\mathrm{P}$ )

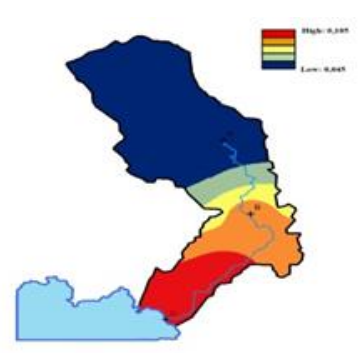

Gambar 2. (Parameter $\mathrm{Cu}$ ) industri dapat merusak ekosistem pada sungai Kampwolker baik di dalam air maupun di sekitar tanah perairan Sungai Kampwolker tersebut. Tiga parameter paling dominan untuk menentukan status mutu air adalah phospat $\left(\mathrm{PO}_{4}-\mathrm{P}\right.$ dengan skor -10$)$, tembaga ( $\mathrm{Cu}$ dengan skor -10$)$, dan timbal $(\mathrm{Pb}$ dengan skor -10) dengan gambar 1. Gambar 1 menjelaskan tentang diagram yang menunjukkan besarnya tiga parameter pada tiga titik sampling.

Data terakhir di bulan April 2019 menunjukan tingkat pencemaran mutu air tersebut sangatlah buruk. Hal ini disebabkan oleh kegiatan yang dilakukan masyarakat sangatlah padat, sehingga kurangnya kesadaran yang tinggi terhadap ekosistem yang ada di dalam sungai Kampwolker tersebut. Hal ini menyebabkan terjadinya banjir dan erosi pada saat intensitas curah hujan yang tinggi dan sungai berubah menjadi warna kecoklatan .

Hasil analisis menunjukan parameter fisika dan kimia menjadi tolak ukur untuk mementukan status mutu air. Parameter yang paling dominan adalah parameter kimia yang terdiri dari phospat $\left(\mathrm{PO}_{4}-\mathrm{P}\right)$ sebesar 2,48 $\mathrm{mg} / 1$ lihat (Gambar 1), tembaga $(\mathrm{Cu})$ sebesar $0,235 \mathrm{mg} / 1$ lihat Gambar (2) dan timbal $(\mathrm{Pb})$ sebesar $0,15 \mathrm{mg} / 1$ lihat (Gambar 3) sehingga dengan menjumlahkan tiga titik sampling menjadi satu konsentrasi tiap parameter.

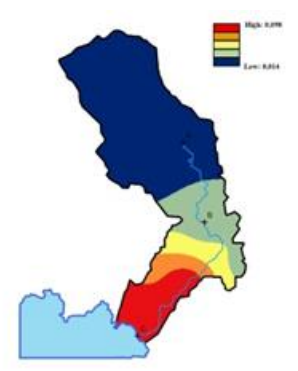

Gambar 3. (Parameter Pb) 
Namun, dari data grafik (Gambar 1) dari penelitian parameter kimia yang paling tertinggi yaitu parameter phospat.

Penjelasan pada gambar 1 untuk parameter phospat $\left(\mathrm{PO}_{4}-\mathrm{P}\right)$ terdapat pada kerak bumi keberadaan fosfor relatif sedikit dan mudah mengendap. Fosfor banyak digunakan sebagai pupuk, sabun atau detergen, bahan industri keramik, minyak pelumas, produk minuman dan makanan, katalis dan sebagainya.

Pada ekosistem air, fosfor terdapat dalam tiga bentuk, yakni senyawa anorganik seperti ortofosfat, senyawa organik dalamprotoplasma, dan senyawa organik terlarut yang terbentuk karena kotoran atau tubuh organisme yang mengurai. Air biasanya mengandung fosfat anorganik terlarut. Fitoplankton dan tumbuhan air lainnya akan mengabsorbsi fosfat ini dan membentuk senyawa, misalnya adenosine trifosfat ATP. Herbivora yang memakan tumbuhan tersebut akan mendapat fosfor tersebut. Jika tumbuhan dan hewan tersebut mati maka bakteri pengurai akan mengembalikan fosfor itu ke dalam air sebagai zat organik terlarut.

Demikian pula dengan kotoran sisa metabolisme hidup dimana akhirnya bakteri menguraikan senyawa organik itu menjadi fosfor (Walukouw, 2010). Kandungan fospat juga diketahui dapat membuat tanaman menjadi tinggi dan subur, karena energi dan unsur yang dibutuhkan dapat terpenuhi, Oleh karena itu, para petani atau pecinta tanaman sering memanfaatkan zat ini untuk kebutuhan pertanian dan taman sehingga jika kelebihan unsur fospat juga dapat memberikan efek kesehatan pada makhluk hidup, terutama manusia yang mengkonsumsi air sungai yang tercemar akan memberikan masalah kesehatan seperti kerusakan ginjal dan osteoporosis. Pada dampak lingkungan, dalam tanah fospat akan bertahan selama beberapa hari sebelum beberapa hari sebelum diubah menjadi zat yang kurang berbahaya. Namun pada tanah yang dalam dan di bagian bawah sungai serta danau, fospat dapat bertahan selama seribu tahun atau lebih lihat gambar 1.

Penjelasan pada gambar 2 untuk parameter $\mathrm{Cu}$ terdapat pada tingginya kadar tembaga $(\mathrm{Cu})$ menggambarkan perairan danau Sentani yang sangat dipengaruhi oleh banjir, erosi dan sedimentasi. kondisi ini akan mengganggu dan berdampak pada keseimbangan ekologis sungai dan danau. Salah satu upaya adalah pengurangan total sumber polutan melalui intervensi fungsional dengan cara mengurangi pertumbuhan populasi di sekitar danau (Walukouw, 2016).

Penjelasan pada gambar 3 untuk Parameter $\mathrm{Pb}$ berasal dari masuknya polutan yang berasal dari rumah tangga, industri, limbah perkotaan, pertanian, perikanan, dan dari kegiatan transportasi (Walukouw, 2017). Sehingga kegiatan tersebut menyebabkan tercemarnya air dan jika dikonsumsi secara berlebihan akibat sungai tercemar dari adanya kandungan timbal dapat berbahaya bagi tubuh terutama ibu hamil karena dapat meningkatkan resiko keguguran, kelahiran prematur, berat badan lahir rendah, dan lambatnya pertumbuhan bayi. Selain itu, ketiga elemen ini saling berhubungan untuk menentukan tingkat kesuburan air. Rasio C: N: P mempengaruhi jaring makanan di perairan, sehingga nilainya berbeda pada tanaman dan bakteri (Walukouw, 2017).

Solusi yang ditawarkan untuk tercemarnya air terutama sungai Kampwolker adalah kurangi penggunaan pestisida berlebihan, melakukan reboisasi agar tidak terkena degredasil lahan atau erosi, kurangi membuang sampah di sungai terutama kemasan-kemasan limbah dari penggunaan konsumsi sampah plastik, membuat IPAL limbah atau di kenal septic tank, melakukan pelatihan pengelolaan sampah dan limbah disekitar kawasan sungai Kampwolker dan menjaga lingkungan disekitar agar terhindar dampak negatif dari sungai itu sendiri.

\section{KESIMPULAN}

Setelah mengetahui kualitas status mutu air sungai Kampwolker dengan menggunakan metode STORET disimpulkan bahwa Sungai Kampwolker menjadi Kategori Kelas berat melebihi batas maksimum $\geq 31$, dengan total skor 48 . Setelah mendapat kualitasnya, pengelolaan sungai tersebut mendapatkan beberapa sampel parameter kimia yang paling dominan tinggi antara lain fospat, tembaga $(\mathrm{Cu})$, dan timbal $(\mathrm{Pb})$. pentingnya ekosistem dan sumber air minum untuk kelangsungan masyarakat di Kota Jayapura tersebut.

Solusi yang ditawarkan untuk tercemarnya air terutama Sungai Kampwolker adalah kurangi penggunaan pestisida berlebihan, melakukan reboisasi agar tidak terkena degredasi lahan atau erosi, kurangi membuang sampah di sungai terutama kemasan-kemasan limbah dari penggunaan konsumsi sampah plastik, membuat IPAL limbah atau di kenal septic tank, melakukan pelatihan pengelolaan sampah dan limbah disekitar kawasan Sungai Kampwolker dan menjaga lingkungan disekitar agar terhindar efek samping dari sungai itu sendiri.

\section{UCAPAN TERIMAKASIH}

Ucapan terima kasih penulis sampaikan untuk semua pihak yang telah memberi dukungan sehingga penulisan jurnal ini dapat diselesaikan.

\section{DAFTAR PUSTAKA}

Mujiati., Pallu, M. S., Maricar. F \& Selintung, M. (2017). Kajian Spasial Penggunaan Lahan dan Kualitas Sungai: Studi Kasus Subdas Kampwolker Papua. Banjarmasin. Universitas Lambung Mangkurat. Prosding Seminar Nasional Lahan Basah Tahun 2016. Volume Jilid 3: 1607-1072

Mujiati. (2015). Studi Perubahan Tata Guna Lahan dan Pengaruhnya Terhadap Kualitas Air Sungai Kampwolker. Universitas Hasanuddin. Disertasi 2017. 
Walukow, A. F. (2008). Analisis Beban Pencemaran dan Kapasitas Asimilasi Danau Sentani, Papua Sebagai Upaya Konservasi Lingkungan Perairan. Berita Biologi. 9(3): 229-235.

Walukow, A. F., Djokosetiyanto, D., Kholil \& Soedarma, D. (2008). Analisis Strategi Pengelolaan dan Peran Lembaga Dalam Rangka Konservasi Danau Sentani Jayapura. Media Konservasi. 13(1): 2131. https://doi.org/10.29243/medkon.13.1.\%p

Walukow, A. F. (2010). Penentuan Status Mutu Air dengan Metode Storet di Danau Sentani Jayapura. Universitas Cenderawasih. Berita Biologi 10 jilid 3Desember 2010

Walukow, A. F. (2010). Kajian Parameter Kimia Posfat di Perairan Danau Sentani Berwawasan Lingkungan .Forum Geografi. 24(2): 196. https://doi.org/10.23917/forgeo.v24i2.5025.
Walukow, A. F. (2012). Analisis Kebijakan Penurunan Luas Hutan di Daerah Aliran Sungai Sentani Berwawasan Lingkungan. Manusia dan Lingkungan. $\quad$ (19)1: 84. https://doi.org/10.22146/jml.18455

Walukow, A. F. (2017). Analysis of Pb Levels as Pollutant in the Waters of the Sentani Lake, Jayapura Indonesia: Study of Determining Water Quality. Der Pharma Chemica, 2017, 9(18):6-8.

Walukow, A. F. (2016.) Analysis of metal concentrations of copper $(\mathrm{Cu})$ in water at sentani lake in jayapura-papua. Der Pharmacia Lettre, 2016, 8 (2): 303-308.

Walukouw, A. F. (2017). Analysis of pollution on physical-chemical parameters and waters environmental quality index using storet index in natural tourism park at youtefa bay, jayapura, indonesia. Der pharma chemica, 2017, 9(9):8-12. 